OPEN ACCESS

Edited by:

Yannis Peter Papastamatiou,

Florida International University,

United States

Reviewed by:

James Ketchum,

Independent Researcher, La Paz,

Mexico

Camrin Braun,

University of Washington,

United States

*Correspondence:

Ryan K. Logan

rlogan@nova.edu;

rklogn@gmail.com

Mahmood S. Shivji

mahmood@nova.edu

Specialty section: This article was submitted to

Marine Megafauna,

a section of the journal

Frontiers in Marine Science

Received: 27 May 2020

Accepted: 12 August 2020

Published: 01 September 2020

Citation:

Logan RK, Vaudo JJ, Sousa LL,

Sampson M, Wetherbee BM and

Shivji MS (2020) Seasonal

Movements and Habitat Use

of Juvenile Smooth Hammerhead

Sharks in the Western North Atlantic

Ocean and Significance for Management.

Front. Mar. Sci. 7:566364.

doi: 10.3389/fmars.2020.566364

\section{Seasonal Movements and Habitat Use of Juvenile Smooth Hammerhead Sharks in the Western North Atlantic Ocean and Significance for Management}

\author{
Ryan K. Logan ${ }^{1,2 *}$, Jeremy J. Vaudo ${ }^{1,2}$, Lara L. Sousa3 ${ }^{3}$, Mark Sampson $^{4}$, \\ Bradley M. Wetherbee ${ }^{1,5}$ and Mahmood S. Shivji ${ }^{1,2 *}$
}

1 Guy Harvey Research Institute, Nova Southeastern University, Dania Beach, FL, United States, ${ }^{2}$ Save Our Seas Foundation Shark Research Center, Nova Southeastern University, Dania Beach, FL, United States, ${ }^{3}$ Wildlife Conservation Research Unit, Department of Zoology, The Recanati-Kaplan Centre, University of Oxford, Tubney, United Kingdom, ${ }^{4}$ Fish Finder Adventures, Ocean City, MD, United States, ${ }^{5}$ Department of Biological Sciences, University of Rhode Island, Kingston, Rl, United States

Upper trophic level predators dramatically impacted by fisheries include the large-bodied hammerhead sharks, which have become species of conservation concern worldwide. Implementing spatial management for conservation of hammerhead populations requires knowledge of temporal distribution patterns and habitat use, identification of essential habitat for protection, and quantification of interactions with human activities. There is little such information for the smooth hammerhead shark, Sphyrna zygaena. We used fin-mounted satellite tags to examine the movements and habitat use of juvenile smooth hammerheads, a demographic segment particularly threatened by exploitation. Six sharks were tagged off the US mid-Atlantic and tracked for 49-441 days (mean $187 \pm 136$ days). Sharks consistently showed area-restricted movements within a summer core area in waters of the New York Bight and a winter core area off Cape Hatteras, North Carolina, with directed movements between them in autumn. There was high overlap of shark winter core area use and the Mid-Atlantic Shark Area (MASA) - a 7 month per year, bottom-longline fishery closure - indicating that this area closure offers seasonal reduction in fishing pressure for this species. Based on timing of shark movements and the MASA closure, protection for juvenile smooth hammerheads may be increased by beginning the closure period 1 month earlier than currently scheduled. Generalized additive mixed models revealed that area-restricted movements of sharks in their summer and winter core areas coincided with high primary productivity, and elevated sea surface temperature. Consistency in use of summer and winter core areas suggests that the coastal waters of the New York Bight and Cape Hatteras, North Carolina could be considered for Essential Fish Habitat designation for this species. This study reveals the first high resolution movements and habitat use for smooth hammerheads in the western North Atlantic to inform management planning for this population.

Keywords: Sphyrna zygaena, movement ecology, behavior, conservation, satellite telemetry 


\section{INTRODUCTION}

The rapid expansion of elasmobranch fisheries and trade globally are principal drivers of population decline for many shark species (Dulvy et al., 2014). Some species, such as the large-bodied hammerhead sharks (great - Sphyrna mokarran, scalloped S. lewini, and smooth - S. zygaena hammerheads), are especially vulnerable to fishing pressure because of their slow rates of population growth (Cortés et al., 2010) and high at-vessel and post-release mortality due to elevated stress response to capture (Morgan and Carlson, 2010; Eddy et al., 2016; Gallagher and Klimley, 2018). In addition, hammerhead sharks are taken in large numbers because of the high demand for their superiorquality fins (large size and high ceratotrichia count) in the global shark fin trade (Abercrombie et al., 2005; Clarke et al., 2006a,b; Cardeñosa et al., 2018). While population declines of the largebodied hammerhead shark species complex is thought to be largely driven by declines of scalloped hammerheads (Jiao et al., 2011), low catch rates in various parts of the world for all species suggest a significant historical decline in the abundance of all large-bodied hammerhead sharks (Baum et al., 2003; Baum and Blanchard, 2010; Ferretti et al., 2010).

Fishery exploitation of smooth hammerhead sharks via targeting or bycatch has been identified as the major threat to this species, particularly for juveniles (Casper et al., 2009; Cortés et al., 2010; Miller, 2016). The conservation of this species is an international priority, e.g., Vulnerable listing on the International Union for Conservation of Nature (IUCN) Red List (Casper et al., 2009); Appendix II listing on the Convention on International Trade in Endangered Species of Wild Fauna and Flora (CITES); Appendix II listing on the Convention on Migratory Species of Wild Animals (CMS). Furthermore, an ecological risk assessment of sharks caught in Atlantic pelagic longline fisheries highlighted smooth hammerheads as a species in urgent need of biological data necessary for stock assessment (Cortés et al., 2010). However, conservation-relevant data on many aspects of the biology of smooth hammerheads are extremely limited, including information relating to their movements, seasonal distributions and habitat use (Miller, 2016; Gallagher and Klimley, 2018).

Achieving sustainable populations of fishery exploited species is critically dependent on the recruitment of immature individuals. Thus, identification and conservation of essential habitat for juvenile and sub-adult sharks is of paramount importance, requiring an understanding of this key demographic segment's spatiotemporal patterns of occurrence and associated oceanic environmental drivers (Kinney and Simpfendorfer, 2009; Schlaff et al., 2014). Equipped with adequate information on how environmental parameters influence seasonal movements, spatial management measures such as temporal closures of targeted areas can be enacted to promote recovery of overfished stocks. For example, based on understanding of temporal and spatial habitat use of dusky sharks (Carcharhinus obscurus), the MidAtlantic Shark Area (MASA) - a region closed to bottom longline fishing for 7 months each year - was established in 2005 as a means of reducing fishing mortality and enhancing recovery of this species (NMFS, 2009).
Smooth hammerheads have a circumglobal distribution in coastal and oceanic waters and occupy a wider latitudinal range than other sphyrnids (Compagno, 1984). Catch records from a variety of locations suggest that juveniles and sub-adults $[<265 \mathrm{~cm}$ total length (TL)] are more common in inshore waters over coastal shelves, with larger individuals $(>265 \mathrm{~cm} \mathrm{TL}$ ) found more frequently offshore (Diemer et al., 2011; Clarke et al., 2015; Francis, 2016; Deacy et al., 2020). This species is capable of long distance movements (e.g., 6,610 km over 150 days; Santos and Coelho, 2018), but also shows high levels of resident behavior within restricted areas (at least 80 days; Diemer et al., 2011).

To date, just two studies have reported on the finer-scale movements of smooth hammerheads via satellite telemetry. Horizontal and vertical movements of juveniles in the temperate western South Pacific appear to vary seasonally (Francis, 2016); in contrast, juvenile and adult smooth hammerheads in the tropical eastern Atlantic demonstrated relatively stable temporal diving behavior (Santos and Coelho, 2018). These studies illustrate the possibility that movements and behavior of smooth hammerheads may be influenced by thermal heterogeneity of their environment. Very little information on relationships between other environmental variables (primary productivity, oceanic fronts, water depth) and movements of smooth hammerheads exists (Couto et al., 2018), although these variables have been shown to greatly influence movement and habitat selection of highly mobile sharks (Block et al., 2011; Queiroz et al., 2016; Vaudo et al., 2017). Understanding interactions between patterns of habitat use and environmental variables would contribute toward construction of habitat models and an improved ability to predict the distribution of smooth hammerheads under climate change scenarios, as well as reveal potential interactions with human activities throughout their range.

Given minimal information on the spatial ecology of smooth hammerheads in general and conservation concerns for this species, our goal was to quantify habitat use and horizontal movements of juvenile smooth hammerheads in the western North Atlantic Ocean via satellite tag telemetry. Only very coarse scale information exists on movements of smooth hammerheads in this region, obtained from the recapture of just seven individuals out of $269(0.02 \%)$ tagged with conventional identification tags over 52 years (Kohler and Turner, 2019). Our study objectives were to: (1) determine seasonal movements and distribution patterns; (2) identify core areas of habitat use; (3) evaluate the potential of the MASA seasonal closure for providing protection from fishing pressure, and (4) investigate relationships between movement behavior and environmental conditions, for juvenile smooth hammerheads.

\section{MATERIALS AND METHODS}

\section{Capture and Tagging}

Between 22 July 2016 and 9 September 2017 six female, juvenile smooth hammerhead sharks were caught via rod and reel off the coast of Ocean City, Maryland United States $\left(38.1^{\circ} \mathrm{N}, 74.5^{\circ}\right.$ W). Sharks were brought on board the fishing vessel where a 
saltwater hose was inserted into the mouth to irrigate the gills and then the sharks were measured, sexed, and fitted with a satellite-linked radio tag (SPOT-196 tag; Wildlife Computers, Redmond, WA, United States) on the dorsal fin. These tags directly communicate with the Argos tracking system ${ }^{1}$ when the shark's dorsal fin breaks the sea surface exposing the tag to air, providing an estimated position (latitude and longitude) and an associated location class. Location class is determined by the number of transmissions received and the number of Argos satellites receiving transmissions, and categorized from most to least accurate as 3, 2, 1, 0, A and B. Estimated errors (1 SD) for each location class are LC 3: < $250 \mathrm{~m}$, LC 2: 250-500 m; LC 1: 500-1500 m, and LC 0: > $1500 \mathrm{~m}$; there is no spatial estimate of accuracy for LC A and B (CLS, 2016). The two tags deployed in 2016 were programmed to transmit for $1 \mathrm{~h}$ every other hour; the four tags deployed in 2017 were programmed to transmit for $1 \mathrm{~h}$ every $4 \mathrm{~h}$ to try to obtain longer duration tracks.

\section{Movements, Distribution, and Behavior}

Because Argos positions of sharks varied in temporal frequency and spatial accuracy, we obtained standardized positions (hereafter "positions") at $12 \mathrm{~h}$ intervals that were comparable between individuals and over time by processing Argos locations using a behavioral switching state-space model (SSM) within a Bayesian framework developed by Jonsen et al. (2005). Since parameter estimation is improved when conducted jointly across multiple individual datasets (Jonsen, 2016), we produced most probable tracks using a hierarchical joint estimation model (hSSM) that produced temporally regular positional estimates based on the Argos location class, mean turning angle, and autocorrelation in speed and direction. Previous research has shown that the accuracy of the hSSM parameter estimates declines in response to outlier locations (from poor quality satellite positions) and long gaps in detection data (Bailey et al., 2008); therefore, prior to fitting hSSMs, each track was filtered using the argosfilter package (Freitas et al., 2008) in R Core Team (2014) with parameters listed in Vaudo et al. (2017). To reduce spurious results associated with long detection gaps, tracks were broken into multiple segments when gaps between Argos locations were $>10$ days. Resulting segments $<20$ days in duration were excluded from the hSSM (Block et al., 2011). Given that $84.7 \%$ of gaps between positions in our tracks were $\leq 12 \mathrm{~h}$ (Supplementary Figure S1), we used a time step of $12 \mathrm{~h}$ in the hSSM to produce two positions per day for each shark.

The hSSM model was fit by running two Markov Chain Monte Carlo (MCMC) chains in parallel for a total of 60,000 samples, with the first 50,000 being discarded as burn-in, and the remaining 10,000 samples thinned by retaining every 10 th sample to reduce autocorrelation ( $n=1,000$ per chain). Each MCMC iteration provides not only a most probable track but also assigns each estimated location to one of two possible behavior modes (resident and transient). The final estimated track is the average of all 2,000 MCMC samples and the final output for each behavioral state represents the proportion of samples for a given position classified as resident (MCMC diagnostics given in Supplementary Figure S5). When the proportion

${ }^{1}$ www.argos-system.org is high (resident) or low (transient) the classification can be confidently assessed. Consequently, following Breed et al. (2009), we classified proportions $\leq 0.3$ as transient, $\geq 0.7$ as resident, and proportions of $0.3-0.7$ as uncertain. The hSSM was fit using the bsam package (Jonsen et al., 2015) in R.

Using the hSSM positions, a seasonal utilization distribution (UD) was calculated for all sharks pooled across the meteorological seasons (summer: June-August, autumn: September-November, winter: December-February, and spring: March-May) using the adehabitat package in $\mathrm{R}$ (Calenge, 2006). The UD estimate was calculated following methods described in Vaudo et al. (2017).

To investigate vertical diel behavior in the absence of transmitted depth data, we used successful Argos transmissions as a proxy for surfacing behavior since locations are only obtained when sharks are at the surface (Doyle et al., 2015). Using the Argos Satellite Pass Prediction tool ${ }^{2}$, satellite pass data was obtained for all six available satellites from June 2017September 2018. Because each satellite can simultaneously detect all transmitters within an approximately 5,000 km diameter circle below it (CLS, 2016), satellite pass data was obtained for $40^{\circ} \mathrm{N}$ and $74^{\circ} \mathrm{W}$, which encompassed all shark positions received. Because the number of satellites passing overhead varies by hour of the day (in effect increasing the amount of listening effort when more satellites are present; Supplementary Figure S2), surfacing behavior was determined by summing the number of Argos locations obtained per shark per hour (Eastern Standard Time), and dividing by the cumulative amount of time that all satellites were overhead during each hour (in general, each satellite takes roughly $10 \mathrm{~min}$ to pass over a stationary object). The resulting value represents a standardized number of Argos locations per hour of satellite coverage (hereafter termed "surfacing index"), providing information on temporal patterns of surfacing, regardless of the number of satellites overhead. The surfacing index (square root transformed) was compared among hours of the day using a linear mixed effects (LME) model as surfacing index $\sim$ hour + ID, where surfacing index was the response variable, hour of day was the explanatory variable and shark ID was a random factor using the lmer function in the lme4 $\mathrm{R}$ package (Bates et al., 2014). Tests of multiple comparisons were obtained using the glht function in the multcomp package (Hothorn et al., 2008). This analysis of diel surfacing behavior was limited to Sharks 3-6 because satellite pass data is only retained by the Argos system for 1 year and this analysis was not undertaken until 2018; thus, satellite pass data could only be obtained for the four sharks tagged in 2017.

\section{Environmental Variables}

Water depth $(\mathrm{m})$ and sea surface temperature (SST; ${ }^{\circ} \mathrm{C}$ ) values were obtained using the NOAA ETOPO1 Global Relief Model (one arc-minute resolution) and the Multiscale Ultra-high Resolution (MUR) SST dataset ${ }^{3}\left(0.01^{\circ}\right.$ resolution), respectively, using the "xtractomatic" package in R (Mendelssohn, 2017). SST gradient (a proxy for temperature fronts) was calculated as the maximum difference in SST

\footnotetext{
${ }^{2}$ https://argos-system.clsamerica.com

${ }^{3}$ http://mur.jpl.nasa.gov/
} 
across a moving window of a $15 \times 15$ grid cell matrix (totaling $\sim 0.15^{\circ}$ area covered) using the raster package (Hijmans et al., 2017) in R. Finally, using the rerddap (Chamberlain et al., 2019) and rerddapXtracto ${ }^{4}$ packages in $\mathrm{R}$, we obtained 8 -day composite primary productivity (PP) ( $\mathrm{mg} \mathrm{C} / \mathrm{m}^{2} /$ day; $0.0125^{\circ}$ resolution) data from the National Aeronautics and Space Administration's (NASA) Aqua satellite with its Moderate Resolution Imaging Spectroradiometer sensor (MODIS-Aqua).

Generalized additive mixed models (GAMMs) were used to determine the best environmental predictors of smooth hammerhead shark resident behavior. Prior to inclusion in the global model, univariate models were constructed with potential environmental predictors standardized by their mean and standard deviation, and tested using a likelihood ratio test. Significant predictor variables were then tested for collinearity using a Pearson's rank correlation matrix (Zuur et al., 2009) and all non-spatial combinations were $<0.7$ (Supplementary Figure S3). The proportion of behavioral states categorized as resident for each position by the hSSM was used as the response variable and all predictor variables were included in the global model. The model was run using a Gaussian response distribution and identity link. The importance of various combinations of autocorrelation structures was tested while holding other variables constant. Similarly, to determine the best random effects structure aimed at accounting for any temporal effect (e.g., increasing temporal gaps between positions since tagging or season) or individual effect imposed on the sharks' behavior, we considered shark ID, season and days at liberty as possible random effects. The performance of the final model output was assessed using the $\mathrm{C}$ index, where values closer to 1 indicate better performance, and the corresponding Somers' Dxy rank correlation, which is a measure of ordinal association between the response and predictor variables (Lea et al., 2018).

\section{RESULTS}

The six juvenile smooth hammerheads TL (mean $\pm S D$ ) $184.2 \pm 18.5 \mathrm{~cm}$ were tracked for periods of 49-441 days and generated a total of 3,488 Argos locations. The number of Argos locations $\mathrm{d}^{-1}$ ranged from 0 to 21 (mean $3.1 \pm 3.3$ ). The mean time interval between Argos positions was $7.7 \pm 33.8 \mathrm{~h}$

${ }^{4}$ https://github.com/rmendels/rerddapXtracto (median $=2.5 \mathrm{~h})$. The number of days with Argos locations for each shark ranged from 46 to 263 days (mean $131 \pm 72.5$ days), resulting in a total of 786 days with locations out of 1121 days at liberty (mean $187 \pm 136$ days) (Table 1). Among all sharks, this equates to being detected on $77.2 \pm 0.1 \%$ of days at liberty. Once the Argos locations were filtered and standardized to a $12 \mathrm{~h}$ time interval using the hSSM, positions were removed for days lacking an Argos location. As a result, 1,531 positions remained, which served as the basis of subsequent analyses.

Most individuals displayed similar movements and habitat use throughout the course of the study (Figure 1A). In general, the hSSM indicated that sharks were resident in shallow water off southern Long Island, New York during the summer, with some southern movement to the waters off New Jersey, Delaware and Maryland in late summer. During autumn, directed southern movements through the mid-Atlantic region were common to all sharks, showing little affinity to any one region in the area, as indicated by the observation that $57 \%$ of positions were classified as transient during autumn. During winter and early spring, sharks displayed area restricted movements, primarily focused near the southeastern outer banks of Pamlico Sound, North Carolina (Figure 1A and Supplementary Figure S4).

One shark (shark \#5), tagged 17 June 2017 was tracked for 441 days (Figure $\mathbf{1 b}$ and Table $\mathbf{1}$ ). This shark was tagged near Ocean City, Maryland and remained there for almost 2 weeks after tagging, then moved north into the New York Bight in early July, where it remained until September when it began a 3 month journey south reaching the area off Cape Hatteras, North Carolina on 15 November. It remained in this area until 3 May 2018 and was not detected again until 9 July 2018 off New Jersey; the shark then moved to waters of the New York Bight until 1 September 2018. Another individual (Shark \#1) moved south from the New York Bight similarly to other sharks, but continued moving south east Cape Hatteras eventually reached the coast of central Florida on 12 December 2016 at the time of the last detection 144 days after tagging (Figure 1a).

Seasonal utilization distributions showed similar seasonal movements as indicated by the hSSM (Figure 2). Core areas (50\% UD) of the seasonal distributions were primarily centered in the New York Bight in the summer, expanded southward during the autumn as sharks moved south, and were concentrated off Cape Hatteras, North Carolina in the winter (Figure 2). The individual tracked for greater than 1 year moved north in late April/early May, in a similar manner to the northward movements of sharks shortly after tagging off Ocean City, Maryland (Figures 1b, 2d).

TABLE 1 | Summary information for SPOT tag deployments on juvenile smooth hammerhead sharks.

\begin{tabular}{|c|c|c|c|c|c|c|c|c|}
\hline Shark ID & TL (cm) & Sex & Date tagged & Tagging location & Days detected & Track duration (days) & Track distance (km) & Argos locations day ${ }^{-1}$ \\
\hline 1 & 221 & $\mathrm{~F}$ & 22-Jul-16 & $38.22,-75.03$ & 126 & 144 & 3305.2 & $6.6 \pm 4.9$ \\
\hline 2 & 183 & $\mathrm{~F}$ & 18-Sep-16 & $38.27,-74.8$ & 118 & 155 & 2554.1 & $3.7 \pm 3.6$ \\
\hline 3 & 163 & $\mathrm{~F}$ & 4-Jun-17 & $37.96,-74.63$ & 139 & 217 & 4359.4 & $2.4 \pm 2.3$ \\
\hline 4 & 173 & $\mathrm{~F}$ & 12-Jun-17 & $37.98,-74.75$ & 94 & 115 & 2252.2 & $2.6 \pm 1.9$ \\
\hline 5 & 190 & $\mathrm{~F}$ & 17-Jun-17 & $37.95,-74.71$ & 263 & 441 & 7319.5 & $2.2 \pm 2.5$ \\
\hline 6 & 175 & $\mathrm{~F}$ & 13-Sep-17 & $38.25,-74.8$ & 46 & 49 & 1345.8 & $3.0 \pm 2.2$ \\
\hline
\end{tabular}

Track distance reflects the sum of distances between estimated track positions. TL: shark total length. 

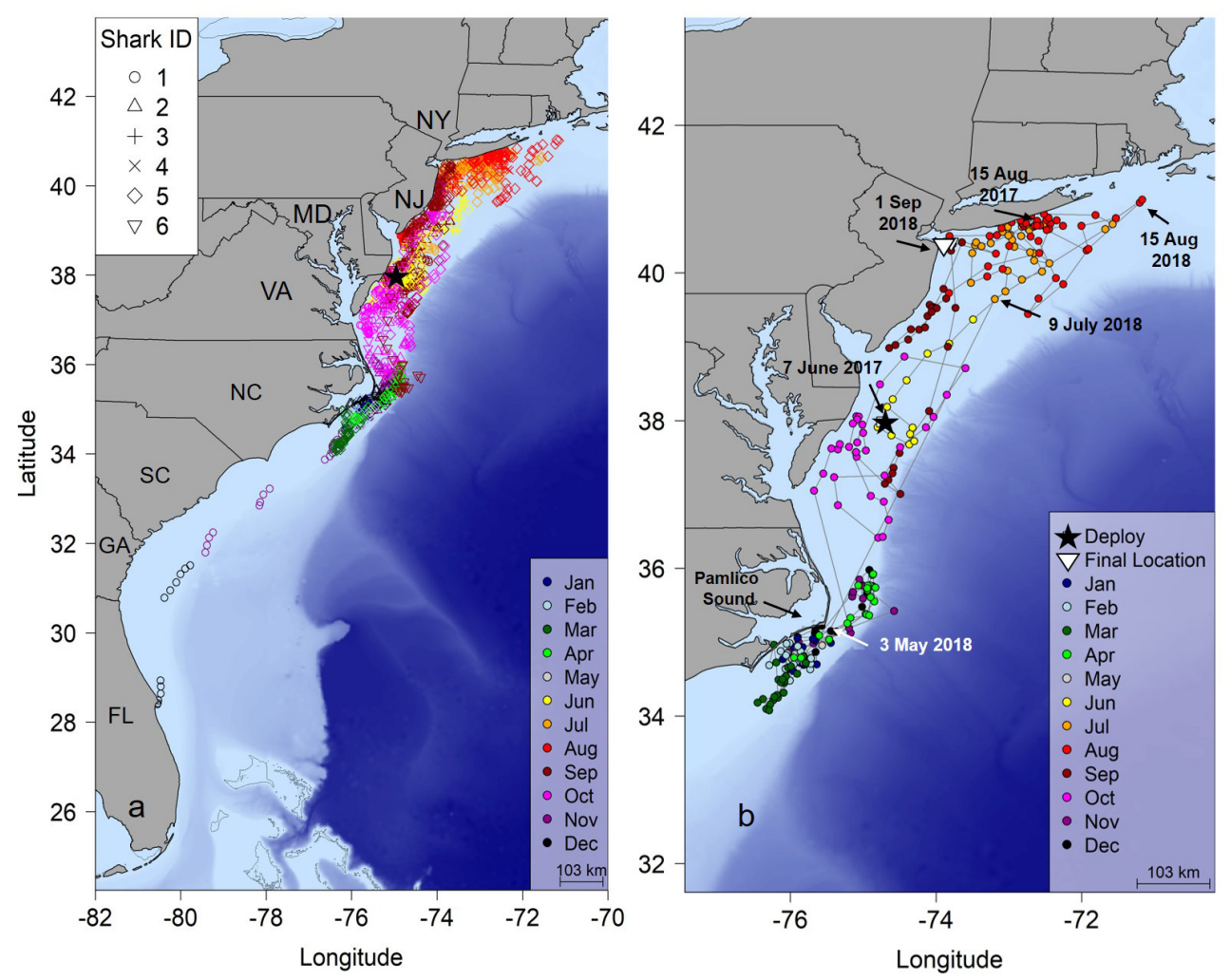

FIGURE 1 | (a) Twelve-hour position estimates for six juvenile smooth hammerhead sharks determined by a hierarchical Bayesian state space movement model (hSSM). (b) Shark \#5 tracked 441 days revealing a complete migration. Black star, tagging location; NY, New York; NJ, New Jersey; MD, Maryland; VA, Virginia; NC, North Carolina; SC, South Carolina; GA, Georgia; FL, Florida.

For sharks with transmissions extending to the winter and spring of the year following tag deployment $(n=4), 96.7 \%$ (315 of 326) of locations fell within the boundaries of the Mid-Atlantic Shark Area (MASA) off North Carolina (Figure 3); 101 (32\%) of these positions occurred during the month of December, when the area is open to commercial bottom longline fisheries (closure period: 1 January-31 July). Positional data was not available to determine when shark \#5 (the individual tracked for $>1$ year) left the MASA (Figure 1b), and transmissions from all other sharks stopped prior to exiting the MASA, so time spent within the MASA could not be assessed.

Because tags (sharks 3-6) deployed in 2017 were programmed to transmit just one out of every $4 \mathrm{~h}$, diel vertical behavior is only described for the hours tags were set to transmit (0000$0100,0400-0500,0800-0900,1200-1300,1600-1700$, and $2000-$ 2100 h). Significant fixed effects for the $0400-0500$ and $2000-$ $2100 \mathrm{~h}$ blocks (0400-0500 LME Estimate $=0.25, \mathrm{SE}=0.07$, $t=3.4, p=0.004 ; 2000-2100$ LME Estimate $=0.23, \mathrm{SE}=0.07$, $t=3.1, p=0.007)$ indicated that surfacing index varied over the $24 \mathrm{~h}$ diel period, and multiple comparisons revealed that sharks surfaced most frequently just before dawn, at midday, and just after dusk (Figure 4). The total number of Argos locations for all sharks pooled was greatest during the time interval 04000500 and $2000-2100 \mathrm{~h}$ (308 and 700 total Argos locations, respectively). The $2000-2100 \mathrm{~h}$ time interval coincided with the greatest number of satellite passes in the study area (all satellites combined $=794$ passes, Supplementary Figure S2), resulting in $165.3 \mathrm{~h}$ of listening time, which yielded an overall surfacing index of 4.23 for all sharks combined. However, although the 0400$0500 \mathrm{~h}$ block only had 40.8 total h of satellite listening time, it had the highest surfacing index of 4.35 for all sharks combined (i.e., on average, there was roughly one position per shark per hour of satellite coverage just before and just after dawn and dusk, respectively; Figure 4).

After testing the importance of various combinations of autocorrelation structures while holding other variables constant, we found that the GAMM without an autocorrelation term was deemed more robust with better wAIC and $\triangle \mathrm{AIC}(\mathrm{wAIC}=0.31$; Supplementary Table S1); thus, no autocorrelation structure was used in the final model. Additionally, wAIC and $\triangle$ AIC revealed that treating shark ID and season as random effects resulted in the most parsimonious model, thus, days at liberty was not included (Supplementary Table S2). The final GAMM predicting residency behavior explained $34 \%$ of the sample variance $(C$ index $=0.72$, Dxy $=0.45, S D=0.001, n=1432)$. Mean SST, log of primary productivity and water depth were included in the best fit model, while SST gradient was removed given its lack of significance $(p=0.2)$ and improved model fit after removal $(\triangle \mathrm{AIC}=2.4$, wAIC $=0.76)$. Model output indicated that most of the variation in the observed resident 


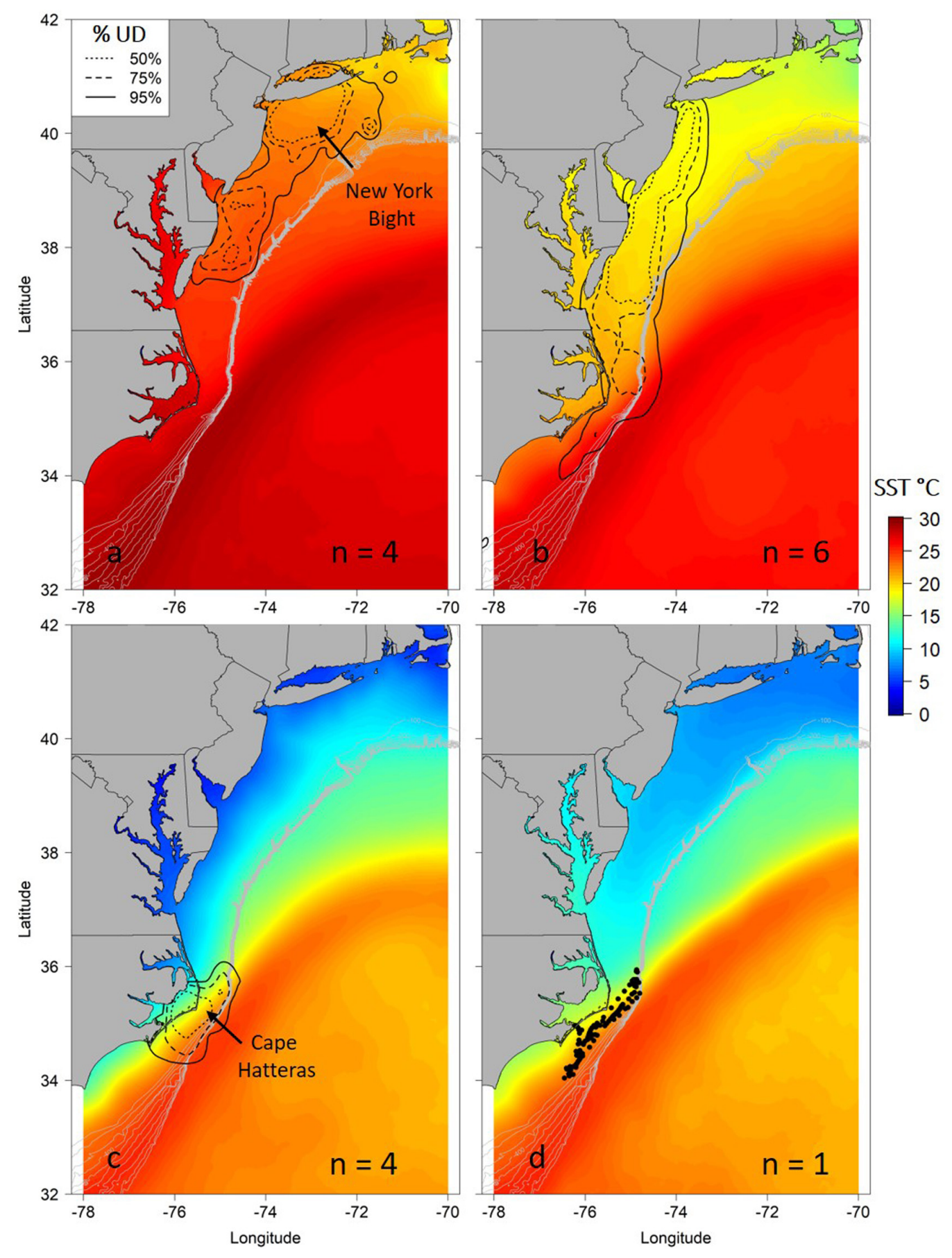

FIGURE 2 | Seasonal utilization distributions (UD) for juvenile smooth hammerhead sharks overlaid on mean seasonal sea surface temperature (SST) during the tracking period. Seasons are summer (a; June-August), autumn (b; September-November), winter (c; December-February) and spring (d; March-May). Solid line is the $95 \%$ UD, dashed line is the $75 \%$ UD and dotted line is the $50 \%$ UD. N refers to the number of individuals that were analyzed in each season. Because only one individual represents the spring locations, points of locations are shown. Gray contour lines represent depth contours from 100 to $1000 \mathrm{~m}$ depth.

behavior was attributable to geographical location, followed by primary productivity concentration and depth (Table 2). Probability of displaying resident behavior was highest at latitudes associated with the New York Bight $\left(>40^{\circ} \mathrm{N}\right)$, high primary productivity concentration $\left[7.82 \log \left(\mathrm{mg} \mathrm{C} / \mathrm{m}^{2} /\right.\right.$ day $)$
(Figure 5B)], and inshore neritic waters ( $<100 \mathrm{~m}$; Figure 5C). In addition, SST of $\sim 18,23$ and $\geq 26^{\circ} \mathrm{C}$ resulted in increased probability of sharks displaying resident behavior as these represented the temperatures experienced in core habitat areas (Figure 5A and Table 2). 


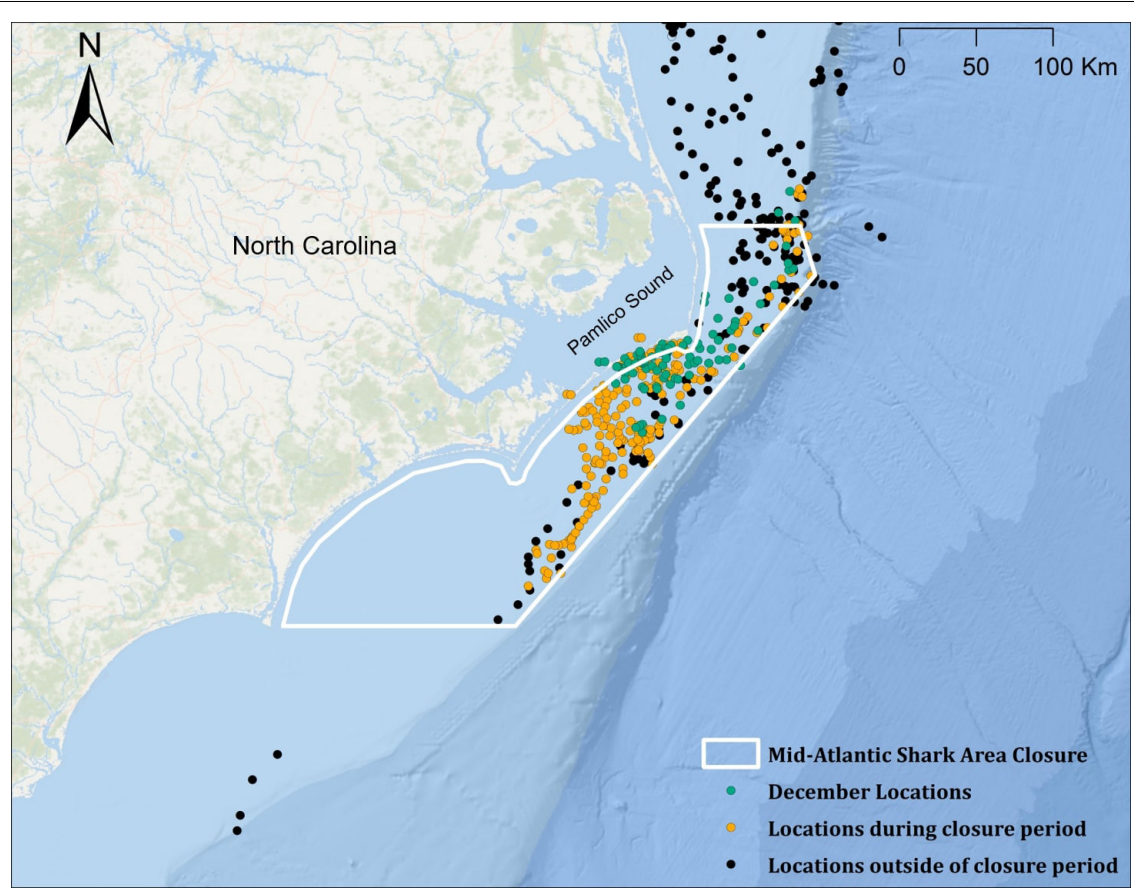

FIGURE 3 | Locations of juvenile smooth hammerhead sharks ( $n=4$ for all groupings) within the mid-Atlantic Shark Area (MASA) during the closure period (January 1-July 1; orange points), and outside of the closure period (black points). Nearly all December locations (green points) fall within the MASA boundary but not within the closure period.

\section{DISCUSSION}

We provide the first detailed view of the movement dynamics of smooth hammerhead sharks in the western North Atlantic. Previous work has reported that smooth hammerhead sharks spend a large proportion of their time in surface or near-surface

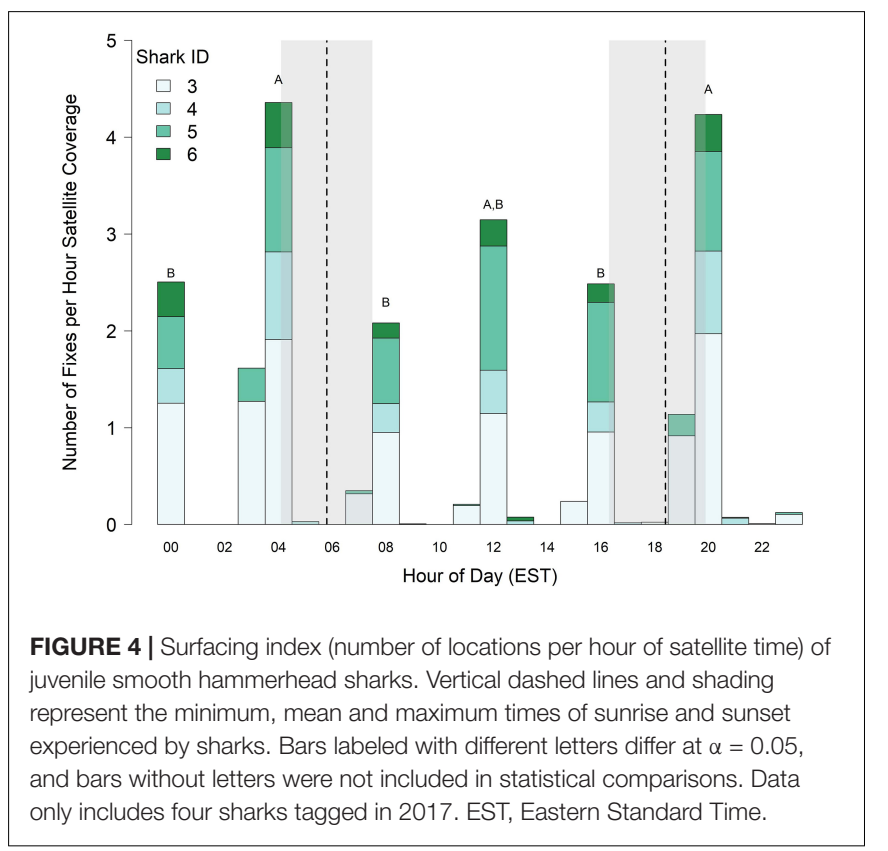

( $<10 \mathrm{~m}$ ) waters (Francis, 2016; Santos and Coelho, 2018), potentially making them good candidates for SPOT tags which only transmit data when exposed to air. Indeed, the sharks tracked here were detected on average $3.1 \pm 3.3$ times per day, and $84.7 \%$ of Argos locations occurred within $12 \mathrm{~h}$ of a previous location. The high frequency of satellite transmissions and Argos locations allowed for reconstruction of smooth hammerhead movements at a much higher resolution than has previously been described.

The sharks we tracked in the western North Atlantic Ocean displayed consistent seasonal movements between core areas of activity off Long Island, New York in summer and off Cape Hatteras, North Carolina in winter. Although seasonal movements of this species have been hypothesized previously based on surface sightings (Couto et al., 2018) and fisheries catch per unit effort data (Santos and Coelho, 2019) in the eastern North Atlantic, the telemetry results here provide a direct, fishery independent demonstration of this behavior by smooth hammerheads. Based on environmental characteristics of the core areas, sea surface temperature and productivity appear to be important drivers of their seasonal movement patterns, as has been demonstrated in other highly migratory marine megafauna (Weng et al., 2008; Block et al., 2011; Curtis et al., 2014; Kajiura and Tellman, 2016; Vaudo et al., 2017).

Seasonal movements and habitat use in other hammerhead species have been documented, but thus far suggest they are driven more so by foraging or reproduction, rather than dynamic oceanographic processes. For example, seasonal changes in abundance of scalloped hammerheads at offshore 
TABLE 2 | GAMM output for juvenile smooth hammerhead resident behavior in relation to environmental variables.

\begin{tabular}{lcccc}
\hline Variable & edf & Ref.df & $\boldsymbol{F}$ & $\boldsymbol{p}$-value \\
\hline s(SST) & 6.8 & 6.8 & 4.2 & $<0.001$ \\
S[log(Primary Productivity)] & 3.9 & 3.9 & 25.3 & $<0.001$ \\
s(Depth) & 1 & 1 & 25.4 & $<0.001$ \\
te(Lon, Lat): Summer & 10 & 10 & 42.1 & $<0.001$ \\
te(Lon, Lat): Autumn & 11.6 & 11.6 & 19.4 & $<0.001$ \\
te(Lon, Lat): Winter & 4.2 & 4.2 & 11.9 & $<0.001$ \\
te(Lon, Lat): Spring & 4.1 & 4.1 & 19.5 & $<0.001$ \\
\hline
\end{tabular}

islands in the eastern tropical Pacific have been suggested as possibly related to movements for reproductive purposes and/or parturition, but currents and chlorophyll concentrations may also play a role in long term movements (Bessudo et al., 2011; Ketchum et al., 2014; Nalesso et al., 2019). Wells et al. (2018) found scalloped hammerhead movements in the northern Gulf of Mexico to be primarily driven by static bathymetric features rather than dynamic environmental variables and did not observe any seasonal patterns in shark movements. Furthermore, great hammerhead repeated seasonal presence and residency within the Bahamas is also believed to be related to reproduction or foraging, rather than climatic processes (Guttridge et al., 2017). However, sharks tracked here represent the juvenile to sub-adult size class of this species, and physiological tolerances to environmental conditions vary across ontogeny and may result in juveniles selecting different habitats than adults (Grubbs, 2010). Given that only one smooth hammerhead in our study was tracked for over a full year, it remains unclear how typical seasonal migratory behavior and environmental driven movement is in this species throughout its geographic and size range.

Seasonal movement patterns of smooth hammerheads along the US East Coast was characterized by resident behavior during the summer and late winter/early spring. The timing of resident behavior coincided with increased levels of primary productivity, presumably tied to prey availability (Ware and Thomson, 2005; Priede and Miller, 2009). Stomach contents show that the major prey of smooth hammerheads is cephalopods (mainly ommastrephid squid) and small schooling fishes (Smale, 1991; Rogers et al., 2012; Bornatowski et al., 2014). The longfin squid Doryteuthis pealeii and shortfin squid Illex illecebrosus are the most common species of squid in the western North Atlantic from Georges Bank to Cape Hatteras, and both species undergo seasonal spawning migrations at northern and inshore locations in late spring/early summer and deeper, southern locations along the continental shelf edge in late autumn/early winter (Dawe et al., 2007; Jereb and Roper, 2010). Seasonal movements and aggregations in relation to high prey abundance has been reported in several species of sharks (Klimley et al., 1992; Heyman et al., 2001; Mourier et al., 2016), however, little information exists on smooth hammerhead diet in the study region to determine if they are taking advantage of this potential resource. Nevertheless, spawning and seasonal movements of these squid in the western North Atlantic spatially and temporally overlap with core areas used by smooth hammerheads tracked in this study.

The diel surfacing behavior patterns of smooth hammerheads tracked in our study may also be related to foraging. Highest surfacing indices were recorded shortly before dawn and after dusk, similar to the pattern observed in a juvenile smooth hammerhead $(139 \mathrm{~cm}$ TL) tracked off the coast of New Zealand (Francis, 2016). Francis (2016) also reported diel differences in depth distribution of another juvenile smooth hammerhead tracked with a popup satellite transmitter, with a shallower distribution at night compared to daylight hours. In contrast, scalloped hammerhead sharks have been observed to remain in shallow waters during the day and dive at night presumably to forage (Klimley and Nelson, 1984; Hoffmayer et al., 2013), or show continuous deep diving behavior throughout the $24 \mathrm{~h}$ cycle (Spaet et al., 2017). Similarly, Santos and Coelho (2018) found that similarly sized smooth hammerheads to those in this study [T-test; $\left.T_{(6.5)}=1.1, p=0.3\right]$ tracked using depth and temperature archival transmitters off the west coast of
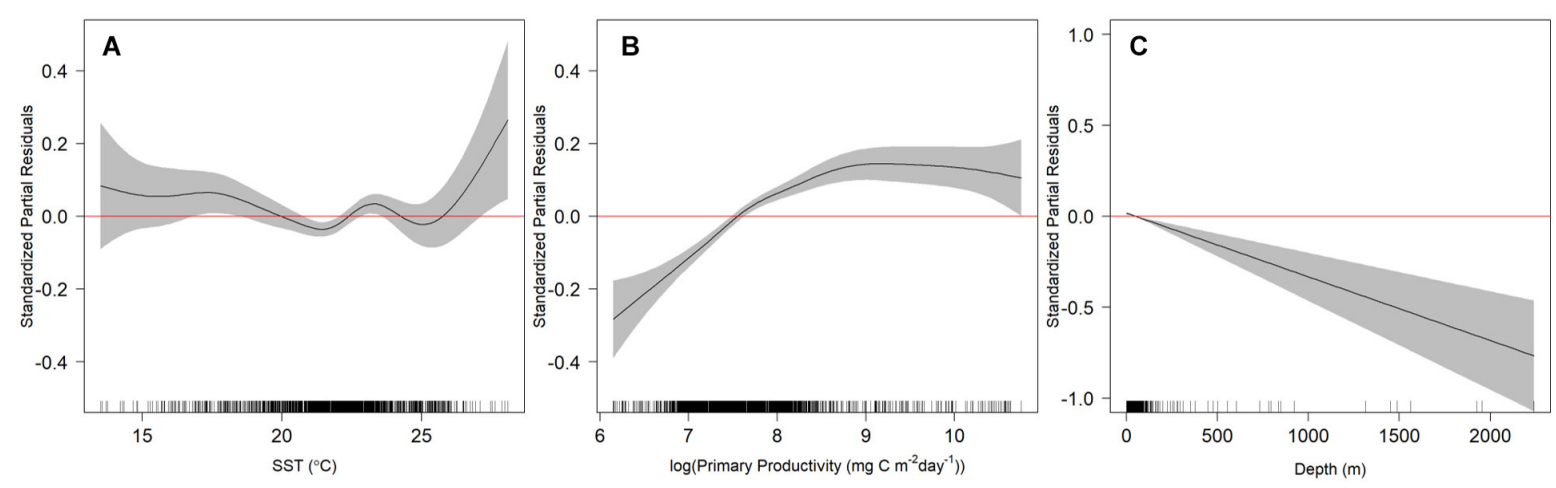

FIGURE 5 | Relationship of sea surface temperature (SST; A), log of primary productivity (B) and seafloor depth (C) with resident behavior exhibited by juvenile smooth hammerhead sharks. Values with 95\% confidence intervals that do not overlap with 0 (red line) indicate either increased (positive values) or decreased probability of resident behavior (negative values; transient behavior). Black ticks along the $x$-axis represent the distribution of the independent variable values examined. Note y-axis scales differ. 
equatorial Africa occupied deeper, cooler water during the night compared to day. Our findings contrast somewhat with those of Santos and Coelho (2018); however, this difference may be an artifact of study location, where sharks tracked in Santos and Coelho (2018) were experiencing temperatures at depth several degrees warmer $\left(26-27^{\circ} \mathrm{C}\right)$ than SSTs observed here in the temperate western North Atlantic (mean $21.7 \pm 2.2^{\circ} \mathrm{C}$ ). In addition, the surfacing index presented here is limited to when a sharks' dorsal fin breaks the surface and appropriate satellite coverage is overhead, so patterns observed here may not be fully representative of smooth hammerhead diel depth distribution in the western North Atlantic.

Decreasing population trends of smooth hammerheads have prompted conservation listings (e.g., IUCN, CITES, CMS) and calls for additional management. Because of high at- vessel (Coelho et al., 2012) and estimated post-release mortality of smooth hammerheads caught in fisheries (Braccini et al., 2012), reducing exposure to capture rather than relying on release after capture is a more effective management method for reduced fishing mortality. While acknowledging that our inferences are based on the four animals with long enough tracks, the consistent finding of the winter core area of activity largely falling within the boundaries of the MASA management zone during winter and spring, and high proportion of transmissions occurring within the MASA during the shark bottom longline fishery closure period (1 January-31 July), suggests the potential of the MASA for reducing fishing mortality of this species. Furthermore, as reported for sand tiger sharks (Carcharias taurus) (Teter et al., 2015), the smooth hammerhead spatial and temporal patterns of movement suggest that beginning the MASA closure on 1 December, rather than 1 January, would provide additional and extended protection from commercial fisheries for this species also.

Though there was some individual variability in movements of smooth hammerheads tracked in our study with a limited number of individuals, the high degree of spatial and temporal consistency demonstrated by the sharks in use of both summer and winter core areas as well as behaviors associated with foraging suggest that the coastal waters of the New York Bight and Cape Hatteras, North Carolina could be considered for designation of Essential Fish Habitat (EFH) for this species in the western North Atlantic, an important designation for protection consideration in U.S. fisheries management practices (NMFS, $2009)^{5}$. Seasonal movement between southern areas of increased presence in winter and northern areas of concentrated activity in summer have been reported for other species of sharks in the western North Atlantic, including sandbar sharks Carcharhinus plumbeus (Grubbs et al., 2007; McCandless et al., 2007; Conrath and Musick, 2008), dusky sharks Carcharhinus obscurus (Musick and Colvocoresses, 1986), sand tiger sharks Carcharias taurus (Teter et al., 2015) and white sharks Carcharodon carcharias (Curtis et al., 2018), and has led to delineation of nurseries and designation of EFH for several of these species (NMFS, 2009). Likely due to the lack of available data, there is currently no EFH in U.S. waters for smooth hammerhead sharks.

\footnotetext{
${ }^{5}$ https://www.fisheries.noaa.gov/resource/map/essential-fish-habitat-mapper
}

Successful management of populations is dependent on the survival of young individuals and recruitment to reproductive stock; therefore, understanding movement patterns, habitat use and EFH of juveniles is vital. In this study we have identified both winter and summer core areas of concentrated activity for juvenile smooth hammerheads in the western North Atlantic, as well as pathways traveled between those seasonal core areas. In addition, environmental conditions associated with resident behavior within these core areas and timing of directed movements between them enables improved ability to predict inter- and intra-annual distribution of smooth hammerheads, and how this may change over time with changing environmental conditions (e.g., increasing sea surface temperatures). These advances in understanding patterns of distribution and habitat use of juvenile smooth hammerheads in the western North Atlantic are directly applicable to effective management of this demographic component of their population. Future work should include studying the movement ecology of adult smooth hammerhead sharks of both sexes since their movements and habitat use patterns are likely to be different from those of juveniles.

\section{DATA AVAILABILITY STATEMENT}

The raw data supporting the conclusions of this article will be made available by the authors, without undue reservation, to any qualified researcher.

\section{ETHICS STATEMENT}

The animal study was reviewed and approved by the Nova Southeastern University IACUC \#DB1.

\section{AUTHOR CONTRIBUTIONS}

BW and MSS designed and implemented the research. MS led the fieldwork. RL led the analysis of the data with assistance from LS and JV. RL led the writing of the manuscript with assistance from all authors.

\section{FUNDING}

This work was supported by grants to MSS from the Guy Harvey Ocean Foundation (GHOF18-1), Save Our Seas Foundation (SOSF157), Shark Foundation/Hai-Stiftung (HF-192), the Levitetz Family Foundation (LFF-19), and a scholarship to RL from Fish Florida.

\section{SUPPLEMENTARY MATERIAL}

The Supplementary Material for this article can be found online at: https://www.frontiersin.org/articles/10.3389/fmars.2020. 566364/full\#supplementary-material 


\section{REFERENCES}

Abercrombie, D. L., Clarke, S. C., and Shivji, M. S. (2005). Global-scale genetic identification of hammerhead sharks: application to assessment of the international fin trade and law enforcement. Conserv. Genet. 6, 775-788. doi: 10.1007/s10592-005-9036-2

Bailey, H., Shillinger, G., Palacios, D., Bograd, S., Spotila, J., Paladino, F., et al. (2008). Identifying and comparing phases of movement by leatherback turtles using state-space models. J. Exp. Mar. Biol. 356, 128-135. doi: 10.1016/j.jembe. 2007.12.020

Bates, D., Maechler, M., Bolker, B., and Walker, S. (2014). Ime4: Linear mixedeffects models using Eigen and S4. R package version 1. doi: 10.18637/jss.v0 67.i01

Baum, J. K., and Blanchard, W. (2010). Inferring shark population trends from generalized linear mixed models of pelagic longline catch and effort data. Fish. Res. 102, 229-239. doi: 10.1016/j.fishres.2009.11.006

Baum, J. K., Myers, R. A., Kehler, D. G., Worm, B., Harley, S. J., and Doherty, P. A. (2003). Collapse and conservation of shark populations in the Northwest Atlantic. Science 299, 389-392. doi: 10.1126/science.107 9777

Bessudo, S., Soler, G. A., Klimley, A. P., Ketchum, J. T., Hearn, A., and Arauz, R. (2011). Residency of the scalloped hammerhead shark (Sphyrna lewini) at Malpelo Island and evidence of migration to other islands in the Eastern Tropical Pacific. Environ. Biol. Fishes 91, 165-176. doi: 10.1007/s10641-0119769-3

Block, B. A., Jonsen, I. D., Jorgensen, S. J., Winship, A. J., Shaffer, S. A., Bograd, S. J., et al. (2011). Tracking apex marine predator movements in a dynamic ocean. Nature 475, 86. doi: 10.1038/nature10082

Bornatowski, H., Braga, R., Abilhoa, V., and Corrêa, M. (2014). Feeding ecology and trophic comparisons of six shark species in a coastal ecosystem off southern Brazil. J. Fish Biol. 85, 246-263. doi: 10.1111/jfb.12417

Braccini, M., Van Rijn, J., and Frick, L. (2012). High post-capture survival for sharks, rays and chimaeras discarded in the main shark fishery of Australia? PLoS One 7:e32547. doi: 10.1371/journal.pone.0032547

Breed, G. A., Jonsen, I. D., Myers, R. A., Bowen, W. D., and Leonard, M. L. (2009). Sex-specific, seasonal foraging tactics of adult grey seals (Halichoerus grypus) revealed by state-space analysis. Ecology 90, 3209-3221. doi: 10.1890/071483.1

Calenge, C. (2006). The package adehabitat for the R software: a tool for the analysis of space and habitat use by animals. Ecol. Modell. 197, 516-519. doi: 10.1016/j.ecolmodel.2006.03.017

Cardeñosa, D., Fields, A. T., Babcock, E. A., Zhang, H., Feldheim, K., Shea, S. K., et al. (2018). CITES-listed sharks remain among the top species in the contemporary fin trade. Conserv. Lett. 11:e12457. doi: 10.1111/conl. 12457

Casper, B., Domingo, A., Gaibor, N., Heupel, M., Kotas, E., Lamonaca, A., et al. (2009). Sphyrna zygaena. The IUCN Red List of Threatened Species. Available a: http://www.iucnredlist.org (Accessed August 16, 2018).

Chamberlain, S., Tupper, B., and Mendelssohn, R. (2019). rerddap: General Purpose Client for 'ERDDAP' Servers, $R$ package version 0.4.2.9130.

Clarke, S., Coelho, R., Francis, M., Kai, M., Kohin, S., Liu, K., et al. (2015). Report of the Pacific Shark Life History Expert Panel Workshop: Final Report. Kolonia: Western and Central Pacific Fisheries Commission Scientific Committee.

Clarke, S. C., Magnussen, J. E., Abercrombie, D. L., McAllister, M. K., and Shivji, M. S. (2006a). Identification of shark species composition and proportion in the Hong Kong shark fin market based on molecular genetics and trade records. Conserv. Biol. 20, 201-211. doi: 10.1111/j.1523-1739.2005.00 247.x

Clarke, S. C., McAllister, M. K., Milner-Gulland, E. J., Kirkwood, G., Michielsens, C. G., Agnew, D. J., et al. (2006b). Global estimates of shark catches using trade records from commercial markets. Ecol. Lett. 9, 1115-1126. doi: 10.1111/j. 1461-0248.2006.00968.x

CLS (2016). Argos Users Manual. Available online at: http://www.argos-system. org/wp-content/uploads/2016/08/r363_9_argos_users_manual-v1.6.6.pdf (accessed September 15, 2018).

Coelho, R., Fernandez-Carvalho, J., Lino, P. G., and Santos, M. N. (2012). An overview of the hooking mortality of elasmobranchs caught in a swordfish pelagic longline fishery in the Atlantic Ocean. Aquat. Living Resour. 25, 311319. doi: $10.1051 / \mathrm{alr} / 2012030$

Compagno, L. J. (1984). Sharks of The World: An Annotated and Illustrated Catalogue of Shark Species Known to Date, pt. 2: Carcharhiniformes. Rome: FAO.

Conrath, C. L., and Musick, J. A. (2008). Investigations into depth and temperature habitat utilization and overwintering grounds of juvenile sandbar sharks, Carcharhinus plumbeus: the importance of near shore North Carolina waters. Environ. Biol. Fishes 82, 123-131. doi: 10.1007/s10641-0079263-0

Cortés, E., Arocha, F., Beerkircher, L., Carvalho, F., Domingo, A., Heupel, M., et al. (2010). Ecological risk assessment of pelagic sharks caught in Atlantic pelagic longline fisheries. Aquat. Living Resour. 23, 25-34. doi: 10.1051/alr/200 9044

Couto, A., Queiroz, N., Ketchum, J. T., Sampaio, E., Furtado, M., Cid, A. A., et al. (2018). Smooth hammerhead sharks (Sphyrna zygaena) observed off the Portuguese southern coast. Environ. Biol. Fishes 101, 1261-1268. doi: 10.1007/ s10641-018-0773-8

Curtis, T. H., Metzger, G., Fischer, C., McBride, B., McCallister, M., Winn, L. J., et al. (2018). First insights into the movements of young-of-the-year white sharks (Carcharodon carcharias) in the western North Atlantic Ocean. Sci. Rep. 8:10794. doi: 10.1038/s41598-018-29180-5

Curtis, T. H., Zeeman, S. I., Summers, E. L., Cadrin, S. X., and Skomal, G. B. (2014). Eyes in the sky: linking satellite oceanography and biotelemetry to explore habitat selection by basking sharks. Anim. Biotelemetry 2:12. doi: 10.1186/20503385-2-12

Dawe, E., Hendrickson, L., Colbourne, E., Drinkwater, K., and Showell, M. (2007). Ocean climate effects on the relative abundance of short-finned (Illex illecebrosus) and long-finned (Loligo pealeii) squid in the northwest Atlantic Ocean. Fish. Oceanogr. 16, 303-316. doi: 10.1111/j.1365-2419.2007.00 431.x

Deacy, B. M., Moncrief-Cox, H. E., and Carlson, J. K. (2020). First verified record of the smooth hammerhead (Sphyrna zygaena) in coastal waters of the northern gulf of mexico with a review of their occurrence in the Western North Atlantic Ocean. South. Nat. 19, 1-7. doi: 10.1656/058.019.0105

Diemer, K., Mann, B., and Hussey, N. (2011). Distribution and movement of scalloped hammerhead Sphryna lewini and smooth hammerhead Sphyrna zygaena sharks along the east coast of southern Africa. Afr. J. Mar. Sci. 33, 229-238. doi: 10.2989/1814232X.2011.600291

Doyle, T. K., Bennison, A., Jessopp, M., Haberlin, D., and Harman, L. A. (2015). A dawn peak in the occurrence of 'knifing behaviour' in blue sharks. J. Anim. Biotelemetry 3:46. doi: 10.1186/s40317-015-0084-1

Dulvy, N. K., Fowler, S. L., Musick, J. A., Cavanagh, R. D., Kyne, P. M., Harrison, L. R., et al. (2014). Extinction risk and conservation of the world's sharks and rays. eLife 3:e00590. doi: 10.7554/eLife.00590

Eddy, C., Brill, R., and Bernal, D. (2016). Rates of at-vessel mortality and post-release survival of pelagic sharks captured with tuna purse seines around drifting fish aggregating devices (FADs) in the equatorial eastern Pacific Ocean. Fish. Res. 174, 109-117. doi: 10.1016/j.fishres.2015. 09.008

Ferretti, F., Worm, B., Britten, G. L., Heithaus, M. R., and Lotze, H. K. (2010). Patterns and ecosystem consequences of shark declines in the ocean. Ecol. Lett. 13, 1055-1071. doi: 10.1111/j.1461-0248.2010.01489.x

Francis, M. (2016). Distribution, habitat and movement of juvenile smooth hammerhead sharks (Sphyrna zygaena) in northern New Zealand. N. Zeal. J. Mar. Freshw. Res. 50, 506-525. doi: 10.1080/00288330.2016.117 1244

Freitas, C., Lydersen, C., Fedak, M. A., and Kovacs, K. M. (2008). A simple new algorithm to filter marine mammal Argos locations. Mar. Mamm. Sci. 24, 315-325. doi: 10.1111/j.1748-7692.2007.00180.x

Gallagher, A. J., and Klimley, A. P. (2018). The biology and conservation status of the large hammerhead shark complex: the great, scalloped, and smooth hammerheads. Rev. Fish Biol. Fish. 28, 777-794. doi: 10.1007/s11160-0189530-5

Grubbs, R. D. (2010). "Ontogenetic shifts in movements and habitat use," in Sharks and Their Relatives II, eds M. Heithaus, J. C. Carrier, and J. A. Musick (Boca Raton, FL: CRC press), 335-366. doi: 10.1201/9781420080 $483-c 7$ 
Grubbs, R. D., Musick, J. A., Conrath, C. L., and Romine, J. G. (2007). "Longterm movements, migration, and temporal delineation of a summer nursery for juvenile sandbar sharks in the Chesapeake Bay region," in Proceedings of the American Fisheries Society Symposium, (Bethesda, MD: American Fisheries Society).

Guttridge, T. L., Van Zinnicq Bergmann, M. P., Bolte, C., Howey, L. A., Finger, J. S., Kessel, S. T., et al. (2017). Philopatry and regional connectivity of the great hammerhead shark, Sphyrna mokarran in the US and Bahamas. Front. Mar. Sci. 4:3. doi: 10.3389/fmars.2017.00003

Heyman, W. D., Graham, R. T., Kjerfve, B., and Johannes, R. E. (2001). Whale sharks Rhincodon typus aggregate to feed on fish spawn in Belize. Mar. Ecol. Prog. Ser. 215, 275-282. doi: 10.3354/meps215275

Hijmans, R. J., van Etten, J., Cheng, J., Mattiuzzi, M., Sumner, M., Greenberg, J. A., et al. (2017). Package 'Raster'. Vienna: R Foundation for Statistical Computing.

Hoffmayer, E. R., Franks, J. S., Driggers, W. B., and Howey, P. W. (2013). Diel vertical movements of a scalloped hammerhead, Sphyrna lewini, in the northern Gulf of Mexico. Bull. Mar. Sci. 89, 551-557. doi: 10.5343/bms.2012. 1048

Hothorn, T., Bretz, F., and Westfall, P. (2008). multcomp: simultaneous inference in general parametric models. R package version 1.4-6. Biometr. J. 50, 346-363. doi: 10.1002/bimj.200810425

Jereb, P., and Roper, C. (2010). Cephalopods of the world. An annotated and illustrated catalogue of species known to date. Volume 2. Myopsid and Oegopsid Squids. Rome: Food and Agriculture Organization of the United Nations.

Jiao, Y., Cortés, E., Andrews, K., and Guo, F. (2011). Poor-data and data-poor species stock assessment using a Bayesian hierarchical approach. Ecol. Applic. 21, 2691-2708. doi: 10.1890/10-0526.1

Jonsen, I. (2016). Joint estimation over multiple individuals improves behavioural state inference from animal movement data. Sci. Rep. 6:20625. doi: 10.1038/ srep20625

Jonsen, I., Bestley, S., Wotherspoon, S., Sumner, M., and Flemming, J. M. (2015). bsam: Bayesian State-Space Models For Animal Movement. $R$ package. $R$ Foundation for Statistical Computing version 0.43. 1.

Jonsen, I. D., Flemming, J. M., and Myers, R. A. (2005). Robust state-space modeling of animal movement data. Ecology 86, 2874-2880. doi: 10.1890/041852

Kajiura, S. M., and Tellman, S. L. (2016). Quantification of massive seasonal aggregations of blacktip sharks (Carcharhinus limbatus) in Southeast Florida. PLoS One 11:e0150911. doi: 10.1371/journal.pone.0150911

Ketchum, J. T., Hearn, A., Klimley, A. P., Peñaherrera, C., Espinoza, E., Bessudo, S., et al. (2014). Inter-island movements of scalloped hammerhead sharks (Sphyrna lewini) and seasonal connectivity in a marine protected area of the eastern tropical Pacific. Mar. Biol. 161, 939-951. doi: 10.1007/s00227-0142393-y

Kinney, M. J., and Simpfendorfer, C. A. (2009). Reassessing the value of nursery areas to shark conservation and management. Conserv. Lett. 2, 53-60. doi: 10.1111/j.1755-263x.2008.00046.x

Klimley, A. P., Anderson, S. D., Pyle, P., and Henderson, R. (1992). Spatiotemporal patterns of white shark (Carcharodon carcharias) predation at the South Farallon Islands, California. Copeia 1992, 680-690. doi: 10.2307/ 1446143

Klimley, A. P., and Nelson, D. R. (1984). Diel movement patterns of the scalloped hammerhead shark (Sphyrna lewini) in relation to El Bajo Espiritu Santo: a refuging central-position social system. Behav. Ecol. Sociobiol. 15, 45-54. doi: 10.1007/bf00310214

Kohler, N. E., and Turner, P. A. (2019). Distributions and movements of atlantic shark species: a 52-year retrospective atlas of mark and recapture data. Mar. Fish. Rev. 81, 1-93. doi: 10.7755/mfr.81.2.1

Lea, J. S., Wetherbee, B. M., Sousa, L. L., Aming, C., Burnie, N., Humphries, N. E., et al. (2018). Ontogenetic partial migration is associated with environmental drivers and influences fisheries interactions in a marine predator. ICES J. Mar. Sci. 75, 1383-1392. doi: 10.1093/icesjms/fsx238

McCandless, C., Pratt, H., Kohler, N., Merson, R., and Recksiek, C. (2007). "Distribution, localized abundance, movements, and migrations of juvenile sandbar sharks tagged in Delaware Bay," in Shark Nursery Grounds of the Gulf of Mexico and the East Coast Waters of the United States, eds C. McCandless,
N. Kohler, and H. Pratt (Bethesda, MD: American Fisheries Society), 45-62.

Mendelssohn, R. (2017). Package 'xtractomatic: Accessing Environmental Data from ERD's ERDDAP Server'. Vienna: $\mathrm{R}$ Foundation for Statistical Computing.

Miller, M. H. (2016). Endangered Species Act Status Review Report: Smooth Hammerhead Shark (Sphyrna zygaena). Silver Spring, MD: National Marine Fisheries Service, Office of Protected Resources.

Morgan, A., and Carlson, J. K. (2010). Capture time, size and hooking mortality of bottom longline-caught sharks. Fish. Res. 101, 32-37. doi: 10.1016/j.fishres. 2009.09.004

Mourier, J., Maynard, J., Parravicini, V., Ballesta, L., Clua, E., Domeier, M. L., et al. (2016). Extreme inverted trophic pyramid of reef sharks supported by spawning groupers. Curr. Biol. 26, 2011-2016. doi: 10.1016/j.cub.2016. 05.058

Musick, J., and Colvocoresses, J. (1986). "Seasonal recruitment of subtropical sharks in Chesapeake Bight, USA," in Workshop on Recruitment in Tropical Coastal Demersal Communities. Intergovenmental Oceanographic Commission Workshop Report 44, eds A. Yanez, Y. Arancibia, and D. Pauley (Campeche: FAO/UNESCO), 301-311.

Nalesso, E., Hearn, A., Sosa-Nishizaki, O., Steiner, T., Antoniou, A., Reid, A., et al. (2019). Movements of scalloped hammerhead sharks (Sphyrna lewini) at Cocos Island, Costa Rica and between oceanic islands in the Eastern Tropical Pacific. PLoS One 14:e0213741. doi: 10.1371/journal.pone.0213741

NMFS (2009). Final Amendment 1 to the 2006 Consolidated Atlantic Highly Migratory Species Fishery Management Plan, Essential Fish Habitat. Silver Spring, MD: NMFS.

Priede, I. G., and Miller, P. I. (2009). A basking shark (Cetorhinus maximus) tracked by satellite together with simultaneous remote sensing II: new analysis reveals orientation to a thermal front. Fish. Res. 95, 370-372. doi: 10.1016/j.fishres. 2008.09.038

Queiroz, N., Humphries, N. E., Mucientes, G., Hammerschlag, N., Lima, F. P., Scales, K. L., et al. (2016). Ocean-wide tracking of pelagic sharks reveals extent of overlap with longline fishing hotspots. Proc. Natl. Acad. Sci. U.S.A. 113, 1582-1587. doi: 10.1073/pnas.1510090113

R Core Team (2014). R: A Language and Environment for Statistical Computing. Vienna: R Foundation for Statistical Computing.

Rogers, P. J., Huveneers, C., Page, B., Hamer, D. J., Goldsworthy, S. D., Mitchell, J. G., et al. (2012). A quantitative comparison of the diets of sympatric pelagic sharks in gulf and shelf ecosystems off southern Australia. ICES J. Mar. Sci. 69, 1382-1393. doi: 10.1093/icesjms/fss 100

Santos, C. C., and Coelho, R. (2018). Migrations and habitat use of the smooth hammerhead shark (Sphyrna zygaena) in the Atlantic Ocean. PLoS One 13:e0198664. doi: 10.1371/journal.pone.0198664

Santos, C. C., and Coelho, R. (2019). Distribution patterns and indicators of the smooth hammerhead shark (Sphyrna zygaena) in the Atlantic Ocean. Fish. Res. 212, 107-113. doi: 10.1016/j.fishres.2018.12.015

Schlaff, A. M., Heupel, M. R., and Simpfendorfer, C. A. (2014). Influence of environmental factors on shark and ray movement, behaviour and habitat use: a review. Rev. Fish Biol. 24, 1089-1103. doi: 10.1007/s11160-0149364-8

Smale, M. (1991). Occurrence and feeding of three shark species, Carcharhinus brachyurus, C. obscurus and Sphyrna zygaena, on the Eastern Cape coast of South Africa. South Afr. J. Mar. Sci. 11, 31-42. doi: 10.2989/02577619178428 7808

Spaet, J. L., Lam, C. H., Braun, C. D., and Berumen, M. L. (2017). Extensive use of mesopelagic waters by a Scalloped hammerhead shark (Sphyrna lewini) in the Red Sea. Anim. Biotelemetry 5:20. doi: 10.1186/s40317-0170135-x

Teter, S. M., Wetherbee, B. M., Fox, D. A., Lam, C. H., Kiefer, D. A., and Shivji, M. (2015). Migratory patterns and habitat use of the sand tiger shark (Carcharias taurus) in the western North Atlantic. Mar. Freshw. Res. 66, 158-169. doi: $10.1071 / \mathrm{mf} 14129$

Vaudo, J. J., Byrne, M. E., Wetherbee, B. M., Harvey, G. M., and Shivji, M. S. (2017). Long-term satellite tracking reveals region-specific movements of a large pelagic predator, the shortfin mako shark, in the western North Atlantic Ocean. J. Appl. Ecol. 54, 1765-1775. doi: 10.1111/1365-2664. 12852 
Ware, D. M., and Thomson, R. E. (2005). Bottom-up ecosystem trophic dynamics determine fish production in the Northeast Pacific. Science 308, 1280-1284. doi: 10.1126/science.1109049

Wells, R., TinHan, T. C., Dance, M. A., Drymon, J. M., Falterman, B., Ajemian, M. J., et al. (2018). Movement, behavior, and habitat use of a marine apex predator, the scalloped hammerhead. Front. Mar. Sci. 5:321. doi: 10.3389/fmars. 2018.00321

Weng, K. C., Foley, D. G., Ganong, J. E., Perle, C., Shillinger, G. L., and Block, B. A. (2008). Migration of an upper trophic level predator, the salmon shark Lamna ditropis, between distant ecoregions. Mar. Ecol. Prog. Ser. 372, 253-264. doi: 10.3354/meps07706

Zuur, A., Ieno, E., Walker, N., Saveliev, A., and Smith, G. (2009). Mixed Effects Models and Extensions in Ecology with R. New York, NY: Springer.
Conflict of Interest: MS was employed by the company Fish Finder Adventures.

The remaining authors declare that the research was conducted in the absence of any commercial or financial relationships that could be construed as a potential conflict of interest.

Copyright (c) 2020 Logan, Vaudo, Sousa, Sampson, Wetherbee and Shivji. This is an open-access article distributed under the terms of the Creative Commons Attribution License (CC BY). The use, distribution or reproduction in other forums is permitted, provided the original author(s) and the copyright owner(s) are credited and that the original publication in this journal is cited, in accordance with accepted academic practice. No use, distribution or reproduction is permitted which does not comply with these terms. 